\title{
Medical students' perspectives on the anatomy course at the University of Zimbabwe
}

\author{
R Siwela, MSc; G Mawera, DPhil \\ Department of Anatomy, College of Health Sciences, University of Zimbabwe, Harare, Zimbabwe
}

Corresponding author: R Siwela (rudosiwela@gmail.com)

Background. Traditional academic-led anatomy teaching methods, such as didactic lectures and cadaver dissections, are on the decline, as more student-led teaching methods are being adopted.

Objectives. To assess medical students' perspectives on the teaching objectives achieved by traditional teaching methods (lectures, cadaver dissections and tutorials) used in the anatomy course.

Methods. A cross-sectional survey comprising a matrix questionnaire was performed among selected 1st-year - 5th-year medical students, using stratified random sampling. The students were requested to select a score between 0 and 5 to represent the fit between the learning outcome and the teaching method, with 0 being no fit and 5 representing a perfect fit.

Results. Lectures had the highest mean score of 3.871 for the ability to provide medical vocabulary. Cadaver dissection had the highest mean score of 3.488 for its ability to develop team skills. The highest mean score of 3.415 for all three teaching methods combined was recorded for the learning outcome relating to imparting an anatomical foundation, while the lowest mean score of 2.731 was recorded for the development of skills in order to follow complicated instructions. However, no teaching method had an excellent fit (mean $\geq 4.5$ ) with any of the teaching objectives.

Conclusion. The study showed that the three teaching methods being used in the anatomy course were, to a great extent, useful to impart the skills and content base. However, other teaching methods, such as problem-based and team-based learning, have to be considered to achieve the other important learning outcomes.

Afr J Health Professions Educ 2017;9(4):176-179. DOI:10.7196/AJHPE.2017.v9i4.822

The teaching of anatomy has been one of the cornerstones of medical education for centuries. ${ }^{[1,2]}$ Knowledge of anatomy assists a physician in examining a patient, determining a diagnosis, and communicating these findings to the patient and other medical professionals. ${ }^{[2]}$

Traditionally, anatomy has been learnt using didactic lectures and practical cadaver dissections. ${ }^{[1,2]}$ Anatomy lectures have been an efficient way of introducing basic concepts and conveying basic knowledge to medical students. ${ }^{[3]}$ Cadaver dissection, on the other hand, has been used to impart an appreciation of 3D anatomy and to familiarise students with the human body. ${ }^{[4]}$ Nonetheless, these methods have been criticised for their inability to convey long-term knowledge, their propensity to overload students with information that may not be necessary for clinical practice, and the associated large expenses for storage, maintenance and disposal of human cadavers. ${ }^{[2,3,5]}$ Therefore, the years spent learning anatomy are seen to be largely labour and resource intensive, but potentially not useful. ${ }^{[2]}$

To counteract the abovementioned pitfalls, the teaching of anatomy has been modified to be less reliant on academic-led teaching, instead emphasising student-led learning, using methods such as problem-based learning (PBL) and team-based learning (TBL). ${ }^{[6]} \mathrm{PBL}$ at its most basic level is a teaching method that uses patient problems as a context for students to learn problem-solving skills and acquire knowledge about the basic and clinical sciences. ${ }^{[7]} \mathrm{TBL}$, however, is a small-group learning method during which students are guided to apply conceptual knowledge through activities that involve individual work, teamwork and immediate feedback. ${ }^{[8]}$ The rationale behind these methods has been that they create a more usable body of knowledge and that the most important medical skills for treating patients are the solving of problems rather than memorising of information. ${ }^{[4,5]}$ These new student-led methods of teaching and their variations are being increasingly embraced by medical schools in developed countries, as they are in line with educational theory ${ }^{[1]}$ Despite the adoption of these student-orientated methods, there is still widespread debate on their pedagogical advantages. ${ }^{[2,9]}$ The small-group sessions in PBL have been shown to suffer from poor attendance, variable student preparation and inconsistent group problem-solving achievement. ${ }^{[10]}$ Furthermore, few students come truly prepared to engage in active discourse and too much time is spent on covering basic factual material rather than applied problem solving. ${ }^{[10]}$

In Africa, there are a few studies on the teaching of anatomy and the modes of instruction. A continental survey of anatomy teaching and the changes in the curricula showed that modern methods of teaching anatomy are being used by a substantial number of medical schools in Africa. ${ }^{[11}$ Eleven of the 19 African departments that responded were using PBL and had converted to this mode of teaching before 2000. ${ }^{[11]}$ In contrast, a review article on anatomy teaching in Africa concluded that 'socioeconomic and political instability, failure to rapidly overcome the inertia for change by substituting the old curriculum with a more problem-based system and student-based one and redefining the goals of medical education are some of the issues of concern for Africa, and its ability to keep up in the dynamic world of medical education. ${ }^{\text {[12] }}$

In line with current modifications in the teaching and assessing of anatomy in medical schools globally, the Department of Anatomy, University 


\begin{tabular}{|c|c|c|c|}
\hline \multirow[b]{2}{*}{ Teaching aim } & \multicolumn{3}{|c|}{ Teaching methods } \\
\hline & $\begin{array}{l}\text { Dissection } \\
\text { by students }\end{array}$ & $\begin{array}{l}\text { Didactic } \\
\text { teaching only }\end{array}$ & Tutorials \\
\hline \multicolumn{4}{|l|}{ 1. To impart an anatomical foundation } \\
\hline \multicolumn{4}{|l|}{ 2. To provide background for clinical disciplines } \\
\hline \multicolumn{4}{|l|}{ 3. To provide medical vocabulary } \\
\hline \multicolumn{4}{|l|}{ 4. To appreciate anatomical variation } \\
\hline \multicolumn{4}{|l|}{ 5. To relate structure to pathology } \\
\hline \multicolumn{4}{|l|}{ 6. To provide student-directed learning } \\
\hline \multicolumn{4}{|l|}{ 7. To develop team skills } \\
\hline \multicolumn{4}{|l|}{ 8. To develop the ability to think and solve problems } \\
\hline 9. To develop skills of following complicated instructions & & & \\
\hline
\end{tabular}

Table 2. Fitness-for-purpose ratings

\begin{tabular}{ll}
\hline Fitness for purpose & Rating \\
\hline Excellent fit & Mean $\geq 4.5$ \\
Good fit & $3.4 \leq$ mean $<4.5$ \\
Moderate fit & $2.5 \leq$ mean $<3.4$ \\
Poor fit & Mean $<2.5$
\end{tabular}

of Zimbabwe needs to make relevant changes to the anatomy course. To improve existing structures and make relevant reforms, a needs assessment has to be done. This will assist in obtaining feedback from students on the strengths and weaknesses of traditional teaching methods, and the learning outcomes that such methods fail to meet. This study, therefore, serves to assess medical students' perspectives on the learning outcomes of the teaching and assessment methods used in the anatomy course at the University of Zimbabwe. This will help in guiding the revision of its anatomy curriculum.

\section{Methods \\ Local context}

The University of Zimbabwe Medical School was established in 1963 as an affiliate of the University of Birmingham, UK. The university's anatomy course is taught in three semesters during the first two preclinical years by the Department of Anatomy. Teaching is done by traditional didactic lectures, practical cadaver dissections, and group tutorials, while in the past 15 years the assessment has been done by multiple-choice-based end-ofregion tests and a final professional multiple-choice question examination at the end of the 2 nd year. The curriculum has remained largely unchanged since the establishment of the medical school, despite major curriculum changes elsewhere in the world.

A cross-sectional survey was carried out at the College of Health Sciences, University of Zimbabwe, Harare, Zimbabwe between August and September 2014. A total of 1063 medical students were registered with the college in the 2014 academic year - 208 students in the 1st year, 303 in the 2 nd year, 225 in the 3 rd year, 212 in the 4 th year, and 115 in the 5 th year. Stratified random sampling was used to choose the students who took part in the study to ensure that they were equitably distributed in accordance with the total number in each class relative to the total number of all students from the 1 st to the 5 th year of study.
Table 3. Demographic data of study participants

\begin{tabular}{lllll}
\hline $\begin{array}{l}\text { MB ChB, } \\
\text { year }\end{array}$ & $\begin{array}{l}\text { Question- } \\
\text { naires } \\
\text { distributed, } \boldsymbol{n}\end{array}$ & $\begin{array}{l}\text { Question- } \\
\text { naires } \\
\text { returned, } \boldsymbol{n}(\%)\end{array}$ & $\begin{array}{l}\text { Question- } \\
\text { naires } \\
\text { disregarded, } \boldsymbol{n}\end{array}$ & $\begin{array}{l}\text { Question- } \\
\text { naires } \\
\text { used, } \boldsymbol{n}\end{array}$ \\
\hline 1 & 150 & $119(79.4)$ & 0 & 119 \\
2 & 210 & $149(71.0)$ & 2 & 147 \\
3 & 160 & $129(80.6)$ & 5 & 124 \\
4 & 150 & $81(54.0)$ & 14 & 67 \\
5 & 80 & $46(57.5)$ & 1 & 45 \\
Total & 750 & $524(69.9)$ & 22 & 502
\end{tabular}

Questionnaires ( $n=750)$ were distributed to the selected 1st-, 2nd-, 3rd-, 4th- and 5th-year medical students. The study instrument was a matrix questionnaire, which was divided into two sections. Section A elicited students' year of study and gender. Section B assessed how well the three teaching methods (didactic lectures, cadaver dissections and tutorials) used in the anatomy course fitted a variety of teaching aims according to Moxham and Moxham. ${ }^{[6]}$ The students were asked to choose a score between 0 and 5 , where 0 represented no fit between the teaching method and the teaching aim and 5 represented a perfect fit (Table 1). Data were collected and entered into a computer. It was cleaned and analysed using the Stata statistical package version 13.0 (StataCorp., USA). Means and standard deviations (SDs) for the scores of each teaching objective for the three teaching techniques were calculated.

The criteria designed by Moxham and Moxham, ${ }^{[6]}$ shown in Table 2, were then used to assess the fitness for purpose of the mean scores between the teaching method and teaching aims. The mean scores for each teaching method were calculated for each teaching aim and the result was compared with the ratings (Table 2$)^{[6]}$ before a decision of whether the fit was excellent, good, moderate or poor was made and entered into a table.

\section{Ethical approval}

Ethical approval to conduct the study was obtained from the Joint Parirenyatwa Hospital and College of Health Sciences Research Ethics Committee, University of Zimbabwe (ref. no. JREC 172/14). Each participating student signed an informed consent form that outlined the objectives of the study, emphasising that participation was voluntary. 


\begin{tabular}{lllll}
\hline & \multicolumn{3}{c}{ Teaching methods } \\
\cline { 2 - 5 } Teaching aim & $\begin{array}{l}\text { Lectures, } \\
\text { mean (SD) }\end{array}$ & $\begin{array}{l}\text { Cadaver dissections, } \\
\text { mean (SD) }\end{array}$ & $\begin{array}{l}\text { Tutorials, } \\
\text { mean (SD) }\end{array}$ & $\begin{array}{l}\text { All three methods, } \\
\text { mean (SD) }\end{array}$ \\
\hline 1. To impart an anatomical foundation & $3.606(1.180)$ & $3.486(1.319)$ & $3.153(1.575)$ & $3.415(1.380)$ \\
2. To provide background for clinical disciplines & $3.337(1.129)$ & $3.078(1.337)$ & $3.088(1.552)$ & $3.167(1.355)$ \\
3. To provide medical vocabulary & $3.871(1.078)$ & $2.944(1.373)$ & $3.225(1.504)$ & $3.347(1.385)$ \\
4. To appreciate anatomical variation & $3.363(1.212)$ & $3.408(1.435)$ & $2.873(1.535)$ & $3.214(1.420)$ \\
5. To relate structure to pathology & $3.082(1.257)$ & $2.902(1.427)$ & $2.815(1.540)$ & $2.932(1.416)$ \\
6. To provide student-directed learning & $2.735(1.424)$ & $3.219(1.446)$ & $3.066(1.638)$ & $3.001(1.518)$ \\
7. To develop team skills & $2.339(1.464)$ & $3.488(1.415)$ & $2.735(1.738)$ & $2.854(1.617)$ \\
8. To develop the ability to think and solve problems & $2.616(1.396)$ & $2.735(1.417)$ & $2.978(1.605)$ & $2.776(1.482)$ \\
9. To develop skills of following complicated instructions & $2.719(1.371)$ & $2.898(1.457)$ & $2.416(1.563)$ & $2.731(1.471)$ \\
SD = standard deviation. & & & &
\end{tabular}

\section{Results}

Of the 750 questionnaires distributed to the study participants, 524 were returned, giving a response rate of $70 \%$. Twenty-two of the questionnaires were disregarded because they were incompletely filled out or the participants failed to follow the instructions. Only 502 questionnaires were used in the final analysis (Table 3).

Table 4 shows the mean scores and SDs for the three teaching methods (lectures, cadaver dissections and tutorials) for the nine different teaching aims.

The results of the fitness for purpose between the three teaching methods and the nine teaching aims are shown in Table 5.

\section{Discussion}

The results of this study showed that none of the three teaching methods had an excellent fit (mean $>4.5$ ) with the nine teaching aims. Cadaver dissection had a good fit with the teaching aims to develop team skills and to appreciate anatomical variation. In addition, it had a moderate fit with all the teaching aims, suggesting that this teaching method had the greatest ability to fulfil all the teaching aims. This supported earlier observations that cadaver dissection was the teaching method that could best achieve most learning outcomes desired in the anatomy course, ${ }^{[6]}$ the reason being that cadaver dissection is able to build both the skills base and content base of students, both of which are important in anatomy. ${ }^{[4]}$ However, the primary concern with cadaver-based learning is the difficulty in acquiring and maintaining enough cadavers. ${ }^{[5]}$ This is notable in Zimbabwe, where the body donor programme has had a low uptake among black Zimbabweans. Furthermore, unclaimed bodies, a main source for anatomy cadavers, are usually decomposed when available for collection by the anatomy department. This is further compounded by the ethical and emotional worries associated with the use of human specimens for teaching purposes and the cultural implications of donating one's body for anatomy teaching. ${ }^{[5]}$

When the individual learning outcomes were analysed, results indicated that lectures had a good fit with teaching aims related to content base, such as imparting an anatomical foundation and providing medical vocabulary. This is explained by the previous observations that didactic lectures are a good platform for teaching the basic language of anatomy to students. ${ }^{[3]}$ Our results are also similar to those of a study of the perspectives of medical
Table 5. Results of fitness for purpose of the three teaching methods and the nine teaching aims

\begin{tabular}{|c|c|c|c|}
\hline \multirow[b]{2}{*}{ Teaching aim } & \multicolumn{3}{|c|}{ Rating } \\
\hline & $\begin{array}{l}\text { Cadaver } \\
\text { dissections }\end{array}$ & Lectures & Tutorials \\
\hline $\begin{array}{l}\text { 1. To impart an anatomical } \\
\text { foundation }\end{array}$ & Moderate & Good & Moderate \\
\hline $\begin{array}{l}\text { 2. To provide background for } \\
\text { clinical disciplines }\end{array}$ & Moderate & Moderate & Moderate \\
\hline 3. To provide medical vocabulary & Moderate & Good & Moderate \\
\hline $\begin{array}{l}\text { 4. To appreciate anatomical } \\
\text { variation }\end{array}$ & Good & Moderate & Moderate \\
\hline 5. To relate structure to pathology & Moderate & Moderate & Moderate \\
\hline $\begin{array}{l}\text { 6. To provide student-directed } \\
\text { learning }\end{array}$ & Moderate & Moderate & Moderate \\
\hline 7. To develop team skills & Good & Poor & Moderate \\
\hline $\begin{array}{l}\text { 8. To develop the ability to } \\
\text { think and solve problems }\end{array}$ & Moderate & Moderate & Moderate \\
\hline $\begin{array}{l}\text { 9. To develop skills of following } \\
\text { complicated instructions }\end{array}$ & Moderate & Moderate & Moderate \\
\hline
\end{tabular}

students on the relationship between course aims or learning outcomes and teaching methods. ${ }^{[6]}$

Several teaching aims, however, were shown not to have a good fit with any of the teaching methods. These included provision of background for clinical disciplines, ability to relate structure to pathology, provision of student-directed learning, ability to think and solve problems, and acquisition of skills of being able to follow complicated instructions. The latter two teaching aims were shown to have the lowest mean scores of all the teaching aims. This can be explained by observations made in earlier studies, which showed that teaching of students using traditional methods was weak in integrating basic anatomy knowledge and practical situations in the clinic. ${ }^{[13,14]}$ Moreover, basic science subjects were reported to be effective only to prepare students for assessments. ${ }^{[14]}$ In addition, the students were reported to be passive learners, lacking initiative with regard to learning and applying anatomy knowledge. ${ }^{[13]}$ 


\section{Conclusion and recommendations}

The study indicated that traditional teaching methods are useful in imparting the content and skills base required in the anatomy course. However, there are some important teaching aims that are not being achieved by the methods used in the anatomy course at the University of Zimbabwe. These are mostly related to the ability to apply anatomy knowledge to clinical scenarios and to enhance the potential to think and solve problems. Therefore, modern teaching methods, such as PBL and TBL, should be incorporated in anatomy teaching to address these observed deficits. This combined approach to teaching and increased co-ordination among different basic and clinical departments might be the answer to a better understanding and application of anatomy knowledge in medical practice in Zimbabwe for the betterment of the health of the society.

Acknowledgements. We would like to thank all the students who participated in the study.

Author contributions. RS was involved in the conceptualisation, design, analysis and interpretation of the data. GM was involved in the design, analysis and interpretation of the data. RS drafted the initial version, and GM critically revised the content. RS and GM both approved the version submitted for publication.

Funding. The Southern Africa Consortium for Research Excellence (SACORE).

Conflicts of interest. None.
. Papa V, Vaccarezza M. Teaching anatomy in the XXI century: New aspects and pitfalls. Sci World J 2013;31:348. https://doi.org/10.1155/2013/310348

2. Turney BW. Anatomy in a modern medical curriculum. Ann R Coll Surg Engl 2007;89(2):104-107. https://doi. org/10.1308/003588407X168244

3. Nagar SK. Newer approaches in anatomy teaching. Natl J Med Res 2012;2(1):17-23.

4. Granger NA. Dissection laboratory is vital to medical gross anatomy education. Anat Rec (New Anat) 2004;281B(1):6-8. https://doi.org/10.1002/ar.b.20039

5. Habbal $\mathrm{O}$. The state of human anatomy teaching in the medical schools of gulf co-operation council countries. SQU Med J 2009;9(1):24-31.

6. Moxham BJ, Moxham SA. The relationship between attitudes, course aims and teaching methods for the teaching of gross anatomy in the medical curriculum. Eur J Anat 2007;11(S1):19-30.

7. Albanese MA, Mitchell S. Problem based learning: A review of literature on its outcomes and implementation issues. Acad Med 1993;68(1):52-81. https://doi.org/10.1097/00001888-199301000-00012

8. Kibble JD, Bellew C, Asmar A, Barkley L. Team based learning in large enrolment classes. Adv Physiol Edu 2016;40(4):435-442. https://doi.org/10.1152/advan.00095.2016

9. Thistlethwaite JEI, Davies D, Ekeocha S, et al. The effectiveness of case-based learning in health professional education A BEME systematic review. BEME Guide No. 23. Med Teach 2012;34(6):e421-e444. https://doi.org/10.3109/014215 9x.2012.680939

10. Nieder GL, Parmelee DX, Stolfi A, Hudes PD. Team based learning in a medical gross anatomy and embryology course. Clin Anat 2005;18(1):56-63. https://doi.org/10.1002/ca.20040

11. Kramer B, Pather N, Ihunwo A. Anatomy: Spotlight on Africa. Anat Sci Edu 2008;1(3):111-118. https://doi. org/10.1002/ase.28

12. Gukas ID. Global paradigm shift in medical education issues: Issues of concern for Africa. Med Teach 2007;29(9):887-892. https://doi.org/10.1080/01421590701814286

13. Schimdt HG, Dauphinee WD, Patel VL. Comparing effects of problem based and conventional curricula in an international sample. J Med Educ 1987;62(4):305-315. https://doi.org/10.1097/00001888-198704000-00002

14. Gupta S, Gupta AK, Verma M, Kaur H, Kaur A, Singh K. The attitudes and perceptions of medical students towards basic science subjects during their clinical years: A cross sectional survey. Int J Appl Basic Med Res 2014;4(1):16-19. https://doi.org/10.4103/2229-516x.125675

Accepted 4 May 2017 